\title{
KIT Protein Variant
}

National Cancer Institute

\section{Source}

National Cancer Institute. KIT Protein Variant. NCI Thesaurus. Code C126819.

A variation in the amino acid sequence for the mast/stem cell growth factor receptor Kit protein. 